\title{
Prognostic Importance of Quantitative Analysis of Coronary Cineangiograms
}

\author{
G. B. John Mancini, MD, Martial G. Bourassa, MD, Paula R. Williamson, BS, Guy Leclerc, MD, \\ Scott F. DeBoe, BS, Bertram Pitt, MD, and Jacques Lesperance, MD
}

Many studies have shown the prognostic value of angiographic data, but few have examined quantitative parameters of wall motion and shape or coronary stenosis severity. To determine whether these parameters have prognostic Importance, baseline angiograms of 283 patients with up to 11.2 years (mean 8.3) of follow-up were quantitated. Event-free survival curves were constructed using log-rank testing. These indexes were also considered in 2 predictive models (Cox regression models): 1 with ("clinical") and 1 without ("quantiative") subjective angiographic analysis and clinical information. Regional shape (anterior and inferior walls) and motion (anterior wall only) indexes were predictive of event-free survival when considered singly. But these parameters were not of independent prognostic importance in the regression models. The most important independent parameters in the quantitative model for predicting overall cardiac mortality or an initial lethal cardiac event were the ejection fraction and the percent diameter narrowing of each major coronary artery. Myocardial infarction was predicted by the percent diameter stenosis of the left main and left anterior descending arteries but not the ejection fraction. In the clinical model, the factors of overriding prognostic importance were the ejection fraction and the subjective determination of the number of vessels involved with "significant" stenoses. Quantitative coronary arteriography still contributed independent prognostic value. Thus, quantification of the ejection fraction and severity of coronary lesions were of independent, prognostic importance, whereas indexes of regional function and shape were not.

(Am J Cardiol 1992;69:1022-1027)

From the Divisions of Cardiology, University of Michigan and Veterans Administration Medical Center, Ann Arbor, Michigan; and the Montreal Heart Institute, Montreal, Quebec, Canada. This study was supported by Grant R01HL36813 from the National Institutes of Health, Bethesda, Maryland. Manuscript received December 2, 1991; revised manuscript received and accepted December 18, 1991.

Address for reprints: G.B. John Mancini, MD, University Hospital, 2211 Wesbrook Mall, Vancouver, British Columbia, Canada V6T 2B5.
1 The need for quantitative and reproducible measurements of global and regional ventricular function and coronary lesion severity is unquestioned in research arenas because visual estimates are highly variable. ${ }^{1}$ Although numerous articles have demonstrated the prognostic importance of a quantitative measure of the ejection fraction as well as some subjectively determined measures of wall motion and stenosis severity, ${ }^{2-11}$ none have determined whether quantitative methods for assessing stenosis severity, wall motion or wall shape have independent prognostic importance. Thus, we set out to determine the prognostic importance of quantitative measures of regional wall motion, wall shape and percent diameter stenosis measurements.

\section{METHODS}

Cineangiograms of 296 patients were randomly selected by investigators at the Montreal Heart Institute from studies of 3,566 patients in the Coronary Artery Surgery Study (CASS) Registry. ${ }^{12}$ Some patients had follow-up data up to 11.2 years (mean follow-up 8.3 years in the entire group). Clinical information was collated on patient characteristics (sex, age, prior myocardial infarction, bypass surgery or angioplasty, number of diseased vessels, location of stenoses). The number of diseased vessels was determined by the original CASS investigators who considered disease to be present when a visually apparent stenosis estimated to be $\geq 50 \%$ was detected.

Cineangiograms were delivered to the Ann Arbor Veterans Administration Medical Center for quantitative analysis using previously developed and validated methods. Cineangiograms were displayed on a Vanguard XR15 Projector interfaced via a video chain to an ADAC 4100C Digital Image Processing Computer (Milpitas, California). Poorly opacified left ventriculograms or studies lacking a non-postectopic beat were excluded from ventricular analysis (13 cases). The largest (end-diastolic) and smallest (end-systolic) ventricular images in the right anterior oblique projection were traced and digitized in a $256 \times 256$ matrix and stored. Global ejection fraction was measured using the arealength method. ${ }^{13}$ Volumes were not measured due to absence of routinely available calibration grids.

Regional wall motion was calculated using the centerline method developed at the University of Washington and previously described in detail. ${ }^{14}$ Briefly, a centerline is drawn midway between the end-diastolic and end-systolic outlines, 100 chords are determined perpendicular to this line and the resultant chord lengths are expressed as a fraction of the end-diastolic silhouette length. These values are then normalized by comparison to regional fractional shortening results of a normal 
population and expressed in standard deviations per chord, averaged over the anterior and inferior regions.

Similarly, regional ventricular shape was measured using a previously described and validated method developed at the University of Michigan. ${ }^{15}$ Briefly, this method calculates the curvature at 100 points along the end-systolic silhouette. Low curvature values denote relatively straight or gently curving regions and high curvature values denote very curved areas such as is seen at the apex of a ventricular silhouettc. The outward bulging of wall motion abnormalities and aneurysms causes an abnormal increase in curvature. In a fashion similar to the wall motion assessment, these curvature values are normalized by comparison to normal shape parameters of a normal population. The regional shape indexes are then reported in standard deviations per point, averaged over the anterior and inferior regions. The optimal threshold values for optimizing sensitivity and specificity of these 2 regional analysis programs have been previously determined at the University of Michigan. ${ }^{15} \mathrm{Op}$ timal concordance between visual and quantitative analysis of wall motion was achieved by using a critical value of -1.1 standard deviations/chord to distinguish between normal or abnormal motion. For shape abnormalities, the critical value was -0.4 standard deviations/point. Therefore, all wall motion and shape results were normalized by these previously determined values so that the numerical results could be more easily compared. The wall motion and wall shape parameters are, therefore, reported in "critical value" units.

The most severe focal lesion in each involved vascular territory designated by the CASS investigators was subjected to quantitative analysis using a previously described and validated method developed at the University of Michigan. ${ }^{16}$ The projection showing the lesion in its most severe perspective and without overlapping side branches was digitized, stored and analyzed. Briefly, the arterial segment and lesion of interest were digitized using 2.4:1 optical magnification into a $512 \times 512$ image matrix and then magnified $\times 2$ by bilinear interpolation. Density profiles perpendicular to a centerline along the longitudinal axis of the segment were analyzed to determine the first and second derivatives of the density profiles. Initial edge points were selected at $75 \%$ of the distance between the second and first derivative locations (i.e., weighted toward the location of the first derivative). These points were automatically examined for spatial continuity. Points that were not within a 4 pixel distance of neighboring edge points were eliminated automatically and replaced by interpolating between edge points on either side of the eliminatcd point. After this automated process, manual editing of the edge was performed when necessary to ensure accurate contour detection. Percent diameter stenosis was calculated by comparing the minimal diameter to the average diameter of a normal, proximal segment. Normal and occluded vessels were designated as having 0 and $100 \%$ diameter stenoses respectively. Absolute measures of lumen size were not recorded owing to lack of information about angiographic catheter size.

Over the term of follow-up, the following complications were recorded: unstable angina, myocardial infarc-

\begin{tabular}{|lc|}
\hline $\begin{array}{l}\text { TABLE I Baseline Characteristics of the Study Group } \\
\text { ( } n=283)\end{array}$ \\
\hline Men/women & $243 / 40$ \\
Age (years) & $51 \pm 8$ \\
Previous myocardial infarction & 184 \\
No. of coronary arteries & \\
narrowed $\geq 50 \%$ in diameter & \\
0 & 4 \\
1 & 85 \\
2 & 98 \\
3 & 96 \\
Location of narrowings & 4 \\
Left main & 216 \\
Left anterior descending & 162 \\
Circumflex & 189 \\
Right & $52 \pm 15$ \\
Ejection fraction (\%) & \\
Wall motion (critical values) & $-1.73 \pm 0.99$ \\
Anterior & $-1.87 \pm 1.01$ \\
Inferior & $-3.20 \pm 2.73$ \\
Wall shape (critical values) & $-1.46 \pm 2.63$ \\
Anterior & \\
Inferior & \\
\hline Continuous data presented as mean \pm standard deviation. \\
\hline
\end{tabular}

tion, congestive heart failure, arrhythmias, syncope, cardiogenic shock, peripheral emboli, stroke and death as well as the cause of death, and need for bypass surgery or angioplasty.

Kaplan-Meier event-free curves were calculated for groups with ejection fractions below 55 and $\geq 55 \%$, anterior and inferior shape or wall motion indexes $\leq-2$ and $>-2$ critical values, and percent diameter stenosis of $<70$ and $\geq 70 \%$ of the left anterior descending, circumflex and right coronary vascular distributions. ${ }^{17}$ Bonferroni adjusted log-rank tests were used to determine the time at which differences in event-free survival curves occurred. ${ }^{18}$ A Cox regression model was used to determine independent predictors of adverse events. ${ }^{19}$ Two specific models were tested. The first, termed the "quantitative model" incorporated only quantitative parameters of ejection fraction, wall motion, wall shape and stenosis severity. The second, termed the "clinical model" incorporated the quantitative parameters as well as the following clinical information: sex, age, prior infarction, number of significantly stenotic vessels by visual analysis (zero, 1-, 2- or 3-vessel disease) or the presence of a stenosis considered to be $\geq 50 \%$ by visual analysis of the left main, left anterior descending, circumflex or right coronary arteries. These models were tested for the prediction of cardiac death at any time during follow-up. In a separate analysis we determined predictors of an initial major cardiac event causing death, and an initial fatal or nonfatal myocardial infarction. In this analysis, we considered the occurrence of arrhythmias, heart failure and unstable angina as adverse events that were likely to have initiated therapies with the potential of altering the patients' prognosis. Similarly, the occurrence of bypass surgery or angioplasty was considered an adverse event because these therapies may have altered subsequent long-term survival or the occurrence of subsequent events, or both. These patients were therefore excluded in the analysis of an initial major cardiac event causing death, and an initial fatal or nonfatal 
myocardial infarction to avoid the potential confounding effects of therapy.

\section{RESULTS}

Cllnical characteristics: Of the original 296 studies, complete angiographic data were obtained in 283 . Table

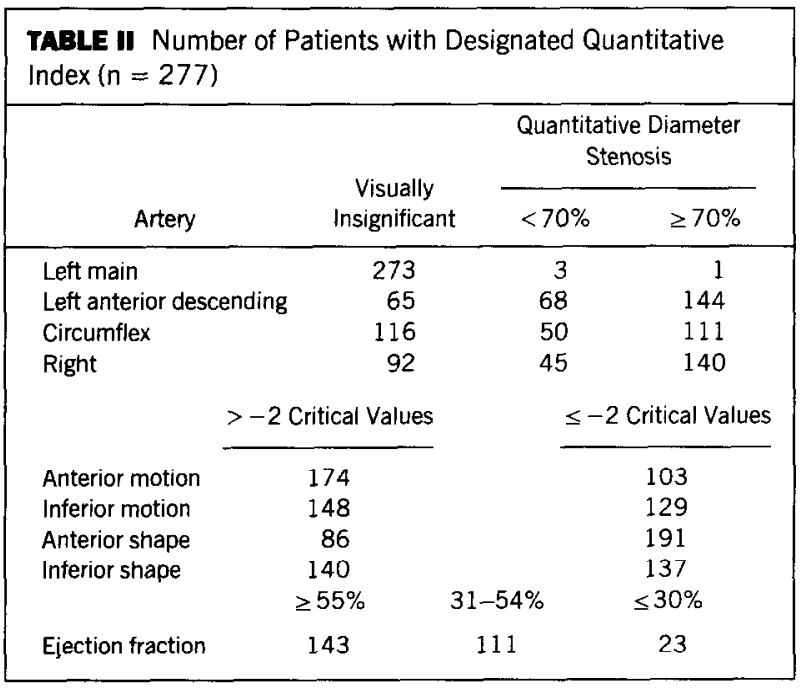

I summarizes characteristics of the study group. At entry, ages ranged from 30 to 68 years, and ejection fractions ranged between 6 and $80 \%$. When visually identified and quantitated, the least severe left main, left anterior descending, circumflex and right coronary lesions were $50,41,41$ and $43 \%$, respectively. The most severe left main stenosis was $75 \%$, whereas in the other territories total occlusions occurred. The average severity of the quantified lesions were as follows: left main $(n=4)$, $61 \pm 15 \%$; LAD $(\mathrm{n}=212), 81 \pm 18$; circumflex $(\mathrm{n}=$ $161), 82 \pm 17 \%$; and right coronary artery $(n=185)$, $86 \pm 18 \%$. Despite a normal mean ejection fraction in this population, mean regional wall motion and shape indexes were abnormal, reflecting the high proportion of patients with prior infarctions (184 of 283). In 6 cases, the exact timing of the first significant cardiac event was unknown. Therefore, all subsequent statistical analyses were based on 277 cases. Quantitative cineangiographic findings in these patients are further summarized in Table II. One hundred forty-three of the 277 cases had ejection fractions $\geq 55 \%$.

For purposes of this study, stroke (16 events) and peripheral emboli (3 events) were considered noncardiac events. One hundred two patients had an event-free follow-up. In the remaining patients, the most frequent

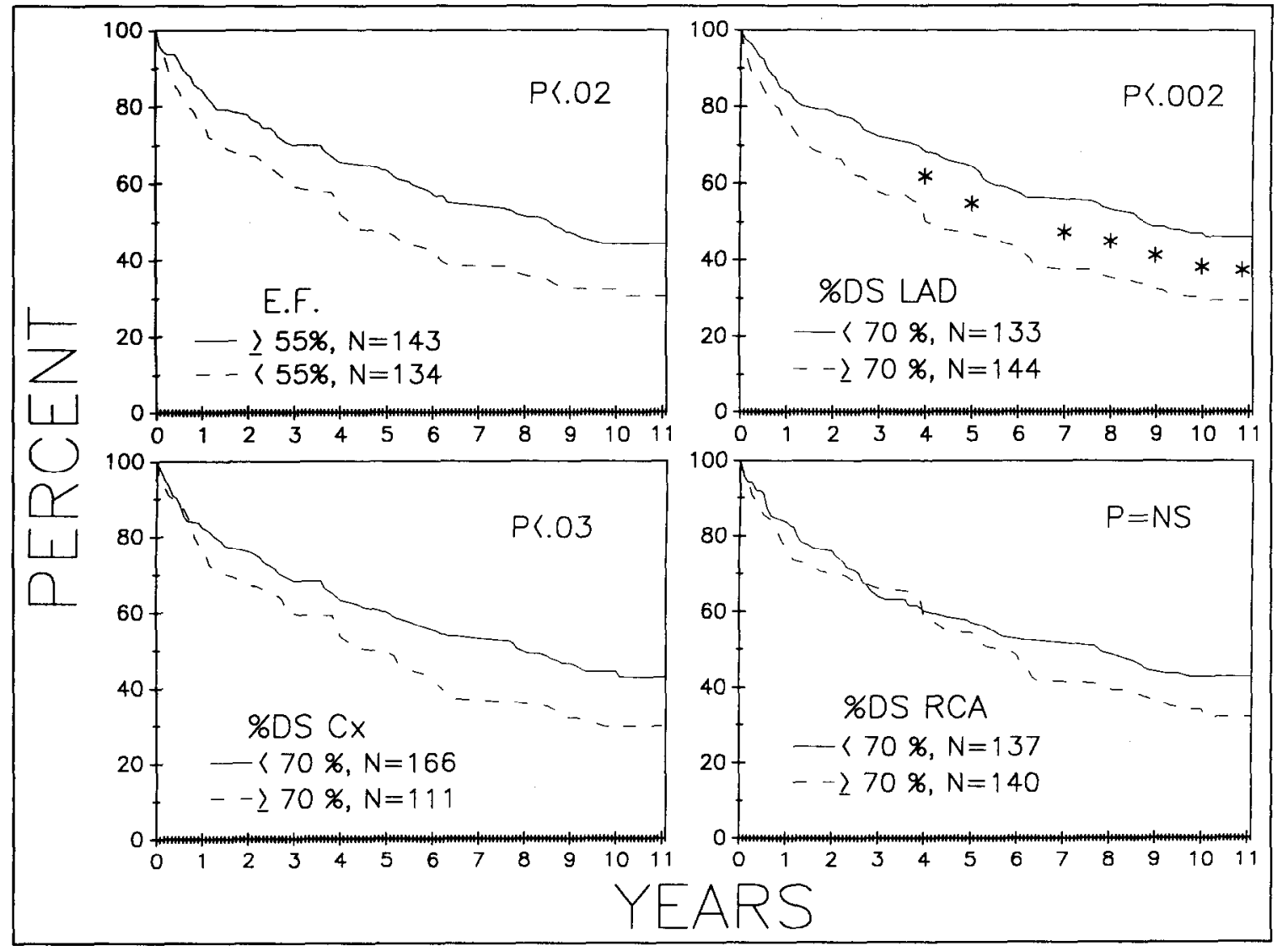

FEURE 1. Event-free survival curves were constructed for groups of patients having normal or abnormal quantitative indexes of election fraction (E.F.) and percent dameter stenosis (DS) of the left anterior descending (LAD), circumflex (CX) and right cor. onary (RCA) arterial beds. N refers to the number of patients with the quantitative index value at the time of the baseline angiogrom. The $y$ axis devignates the percent of the original number of patients with event-free survival. The $x$ axis is given in years. Stenificant overal differences are designated by the p values which are based on log-rank tests. Symbols between curves desigmate spectific the points when the curves are statistically different based on Bonferroni adjustments of the log-rank test. NS = not steminicant; *p <0.05. 
event was the onset of unstable angina in 63 patients ( 85 occurrences) followed by bypass surgery in 74 patients ( 77 occurrences) and myocardial infarction in 53 (73 occurrences). Congestive heart failure events were documented 44 times. Sudden death occurred in 25 patients. Significant arrhythmias excluding ventricular tachycardia were noted on 14 occasions and there were 5 episodes of ventricular tachycardia. Cardiogenic shock was noted 13 times. A single percutaneous coronary angioplasty reflects the emergence of the technique after the time of patient enrollment and during the course of the follow-up.

In addition to the 25 sudden deaths, there were 19 fatal myocardial infarctions (14 of which were the initial event after angiography), 7 deaths due to congestive heart failure, 6 deaths ascribed to cardiogenic shock and 2 ascribed to ventricular tachycardia. Stroke accounted for 7 deaths. In 18 cases the cause of death was not specified.

Event-free survival curves were constructed for the quantitative indexes and are demonstrated in Figures 1 and 2 . The event-free survival curves were significantly different with respect to each of the quantitative parameters except in the case of inferior wall motion, and percent diameter stenosis of the right coronary artery. Significant overall differences in the event-free survival curves $(\mathrm{p}<0.02)$ between patients with and without a normal ejection fraction ( $\geq 55 \%)$ were found, but these curves were not significantly different at any specific time point during the follow-up period. The curves based on anterior wall motion were also significantly different $(p<0.003)$ and, in contrast to the ejection fraction curves, diverged significantly from the fourth year to the end of the follow-up period. Anterior shape abnormalities were also associated with a worse, overall event-free survival $(p<0.004)$ and the curves were specifically divergent from the third year on. Inferior wall shape abnormalities also imparted a worse, overall event-free survival $(p<0.007)$, but the curves did not diverge significantly at any specific time except at the end of the follow-up period. Patients with left anterior descending territory stenoses that were $<70 \%$ had a better event-free survival than those with more severe stenoses ( $p<0.002)$. These curves diverged significantly from the fourth year on, except in year 6 when the curves did not quite reach statistically significant differences. Patients with stenoses of the circumflex that were $<70 \%$ also had a better event-free survival ( $p<0.03$ ), but these curves were not statistically divergent at any specific time point. There were 59 cardiac deaths occurring during the entire follow-up period, and 37 of these deaths were in fact the initial cardiac event during follow-up. Myocardial infarction was the initial significant cardiac event during follow-up in 42 cases and 14 of these were fatal. In the "quantitative" model (Table III), the ejection fraction was of overriding importance in predicting overall cardiac death and an initial, lethal cardiac event. However, all of the quantitative percent

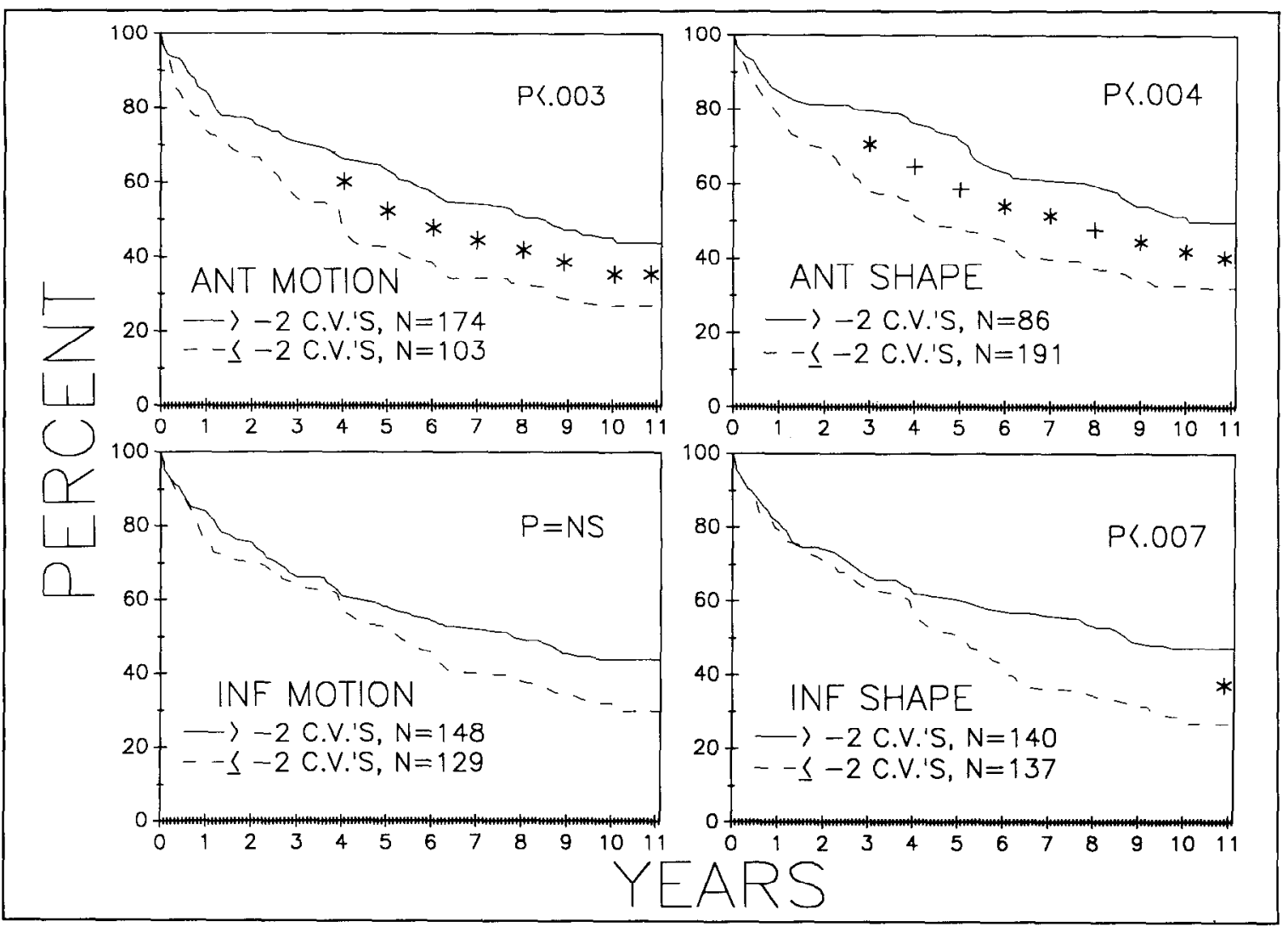

FIGURE 2. Event-free arvival curves were constructed for groups of patients having normal or abnormal cuantitative indexes of regional wall motion or regional shape on their baseline ventriculogram. ANT = amterior; INF = inferior; C.V.'S = critical values; $+p<0.01$; other abbreviations and format as in Figure 1. 
TABLE III Summary of Factors Predicting Clinical Outcomes, Ranked in Order of Importance, for the Quantitative Model

\begin{tabular}{|lll|}
\hline \multicolumn{1}{|c}{ Parameter } & Coefficient & p Value \\
\hline Cardiac death & & \\
$\quad$ Ejection fraction & 2.82 & 0.0001 \\
\% diameter stenosis: & & \\
$\quad$ Circumflex & 1.51 & 0.005 \\
$\quad$ Left main & 4.06 & 0.03 \\
$\quad$ Left anterior descending & 1.52 & 0.02 \\
$\quad$ Right & 1.42 & 0.02 \\
Initial lethal cardiac event & & \\
Ejection fraction & 2.56 & 0.00001 \\
\% diameter stenosis: & & \\
$\quad$ Left anterior descending & 2.16 & 0.0001 \\
$\quad$ Right & 1.58 & 0.02 \\
$\quad$ Circumflex & 1.54 & 0.03 \\
$\quad$ Left main & 3.81 & 0.04 \\
Myocardial infarction & & \\
\% diameter stenosis: & & 0.04 \\
$\quad$ Left main & 4.11 & 0.04 \\
Left anterior descending & 1.18 & \\
\hline
\end{tabular}

diameter stenosis variables were also independently predictive. In contrast, none of the wall function indexes was predictive. Myocardial infarction was predicted by the percent diameter stenosis of left main and left anterior descending lesions but not the ejection fraction.

Results of the "clinical" predictive model demonstrated the overriding importance of the quantitated ejection fraction in predicting overall cardiac death (coefficient $=3.08, p<0.00001$ ), followed by the number of vessels diseased (coefficient $=2.03, p<0.0001$ ) and the patients' age (coefficient $=1.05, \mathrm{p}<0.009$ ). An initial, lethal cardiac event was predicted, in order of importance, by the ejection fraction, the number of vessels diseased and the quantitative percent diameter stenosis of the left anterior descending artery (coefficients = $2.78,2.16,1.69, \mathrm{p}<0.00001,0.0006,0.05$, respectively). Myocardial infarction was predicted by both the qualitative presence of a significant stenosis in the left anterior descending artery (coefficient $=3.88, p$ $<0.002$ ) and the quantitative percent diameter stenosis of the left main artery (coefficient $=3.79, \mathrm{p}<0.05$ ).

\section{DISCussion}

Many prior analyses have shown the prognostic importance of the quantitative ejection fraction, but the purported value or lack of value of other parameters of regional function and stenosis severity were uniformly based on qualitative assessments. ${ }^{3-12}$ This study was motivated by a desire to put into perspective several of the currently available quantification methods that are applied to cineangiograms and to determine whether such parameters have prognostic power. We assessed this in a population with well-defined, long term, clinical follow-up. Our a priori expectation was that sophisticated parameters of ventricular function and shape would be of overriding clinical importance and that quantitative coronary arteriography would provide little, if any, prognostic power. But the results were quite different. In general, the simple ejection fraction remained the prime determinant of most cardiac syndromes, and sophisticated measures of regional wall motion and shape were not of independent prognostic value. Surprisingly, quantitative coronary arteriography was of independent prognostic value in both the clinical and quantitative regression models.

Groups dichotomized with respect to most quantitative parameters showed significant differences in eventfree survival over the decade of follow-up. Exceptions occurred in the case of percent diameter stenosis of the right coronary artery and inferior wall motion. The most highly divergent curves were associated with anterior shape analysis, anterior wall motion analysis and percent diameter stenosis of the left anterior descending coronary artery territory.

The Cox regression models, however, serve to put these univariate results into perspective by demonstrating the overriding importance of the ejection fraction. ${ }^{5-10,20}$ Despite this, other factors were also of independent, prognostic importance. These were generally not related to more detailed or sophisticated measures of regional function or shape and this is almost certainly because these parameters are highly correlated with the less complex ejection fraction calculation. Instead, the quantitative measures of percent diameter stenosis, especially of the left anterior descending coronary bed or the left main coronary artery were the parameters that contributed additional and independent prognostic value. This was particularly the case when considering initial, lethal cardiac events or myocardial infarction.

A recent study has made the provocative observation that severe lesions are often not the sites of subsequent occlusion and causation of myocardial infarctions. ${ }^{21}$ Others have shown an association between lesion severity and infarction. ${ }^{22}$ The current study suggests that over a long follow-up period, the quantitative severity of coronary lesions, especially of the left main or left anterior descending artery, is indeed predictive of infarction. Whether these severe lesions are actually the sites of occlusion leading to infarction cannot be established from the current study because follow-up angiograms were not available. One can only conclude that the presence of severe lesions portends a higher risk of subsequent infarction.

Regional function and shape indexes are often used in studies of thrombolysis. These studies often focus on segmental effects and minimize attention to either arteriographic findings or overall ejection fraction measurements. However, because these parameters were eliminated in both the clinical and quantitative models, one must question the use of isolated measures of wall function as surrogate end points in many clinical trials. Our results suggest that these parameters should not be evaluated separately from the quantitative coronary arteriographic results and that the overall ejection fraction results in such studies should never be deemphasized. ${ }^{23}$

The clinical model was chosen because it approximates the cognitive aspects of clinical decision making that take into account many factors influencing the interpretation of test results. ${ }^{24}$ Thus, this model included patient age, sex, the presence of prior infarction and subjective assessments of the number of vessels with "significant" stenoses, and their location. These are not 
the only factors and perhaps not even the main factors that a practicing cardiologist would use to make an overall clinical assessment of risk or a clinical decision regarding therapy. For example, results of exercise testing and especially functional radionuclide studies commonly sway clinical decisions, and such results were not incorporated into this study. In this context, although the ejection fraction and the number of diseased vessels are the most consistent and important determinants of adverse clinical outcomes, quantitative coronary arteriography was of independent, prognostic power, whereas wall motion and shape analyses were not.

The percent diameter stenosis parameter, even measured meticulously, has been roundly criticized in recent years based on (1) recognition of the diffuse nature of atherosclerosis and the resultant difficulty in selecting normal reference diameters ${ }^{25}$; (2) the fact that such measurements do not take into account other important morphologic features such as length or entrance and exit angles ${ }^{26}$; (3) the realization that many stenoses are eccentric and cannot be accurately represented by a single plane measurement ${ }^{25}$; (4) the new knowledge that remodeling and dilatation of vessels occurs in response to atherosclerosis ${ }^{27}$; and (5) the imprecise relation between this parameter and other directly measured indexes of functional stenosis severity. ${ }^{28,29}$ Whereas all of these arguments are cogent, this study suggests that percent diameter stenosis, much like the ejection fraction with its well-recognized limitations, is still of tremendous prognostic importance and is an appropriate parameter upon which to base routine clinical judgments. ${ }^{24}$ Much greater experience and long-term followup analyses, such as the one presented in this study, will need to be undertaken with the alternative proposed indexes of stenosis severity before replacing the simple quantification of percent diameter stenosis.

This study should not be interpreted to imply any potential "superiority" of quantitative arteriography over subjective stenosis assessment. However, neither should the visual assessment of presence and severity of stenoses by the original CASS investigators be equated with the more casual day-to-day assessments used in practice. Nevertheless, because only the quantitative methods are associated with a high degree of reproducibility, and because these parameters have now been shown by this study to have prognostic importance, one may conclude that such quantitative measures would be suitable not solely for research purposes, but also for clinical decision-making if the indexes could be obtained expeditiously and within practical constraints. This study therefore provides a clinically relevant reason, beyond merely that of enhanced reproducibility, to promote the development of quantitative and verifiable methods that can be used easily in clinical practice. ${ }^{30}$

\section{REFERENCES}

1. Detre KM, Wright E, Murphy ML, Takaro T. Observer agreement in evaluating coronary angiograms. Circulation 1975;52:979-986.

2. Burggraf GW, Parker JO. Prognosis in coronary artery disease. Circulation 1975;51:146-156.

3. Humphries JO, Kuller L, Ross RS, Fresinger GC, Page EE. Natural history of ischemic heart disease in relation to arteriographic findings. Circulation 1974;
49:489-497.

4. Reeves JT, Oberman A, Jones WS, Sheffield LT. Natural history of angina pectoris. Am J Cardiol 1974;33:423-430.

5. Hammermeister KE, DeRouen TA, Dodge HT. Variables predictive of survival in patients with coronary disease: prediction by univariate and multivariate analyses from the clinical electrographic, exercise, arteriographic and quantitative angiographic evaluations. Circulation 1979;59:421-430.

6. Harris PJ, Phil D, Behar VS, Conley MJ, Harrell FE, Lee KL, Peter RH, Kong $Y$, Rosati RA. The prognostic significance of $50 \%$ coronary stenosis in medically treated patients with coronary artery disease. Circulation 1980;62:240-248.

7. Kennedy JW, Kaiser GC, Fisher LD, Fritz JK, Myers W, Mudd GJ, Ryan TJ. Clinical and angiographic predictors of operative mortality from the collaborative study in coronary artery surgery (CASS). Circulation 1981;63:793-802.

8. Mock MB, Ringovist I, Fisher LD, Davis KB, Chaitman BR, Kouchoukos NT, Kaiser GC, Alderman E, Ryan TJ, Russell RO, Mullin S, Fray D, Killip T, and the participants in the Coronary Artery Surgery Study. Survival of medically treated patients in the Coronary Artery Surgery Study (CASS) registry. Circulation 1982;66:562-568.

9. Sanz G, Castaner A, Betrui A, Magrina J, Roig E, Coll S, Pare JC, NavarroLopcz F. Detcrminants of prognosis in survivors of myocardial infarction: a prospective clinical angiographic study. $N$ Engl J Med 1982;306:1065-1070.

10. Califf RM, Tomabechi Y, Lee KL, Phillips H, Pryor DB, Harrell FE, Harris PJ, Phil D. Peter RH, Behar VS, Kong Yihong, Rosati RA. Outcome in 1-vessel coronary artery disease. Circulation 1983;67:283-290.

11. Proudfit WJ, Bruschke AVG, MacMillan JP, Williams GW, Sones FM Fifteen year survival study of patients with obstructive coronary artery disease. Circulation 1983;68:986-997.

12. Principal Investigators of CASS and their associates. The National Heart, Lung and Blood Institute Coronary Artery Surgery Study. Circulation 1981:63 (suppl).I-1-I-181.

13. Sandler H, Dodge HT. The use of single plane angiocardiograms for the calculation of left ventricular volume in man. Am Heart $J$ 1968;75:325-334.

14. Bolson EL, Kliman S, Sheehan FH, Dodge HT. Left ventricular segmental wall motion: a new method using local direction information. IEEE Comput Cardiol 1980;245-248.

15. Mancini GBJ, DeBoe SF, Anselmo E, LeFree MT, Vogel RA. A comparison of traditional wall motion assessment and quantitative shape analysis: a new method for characterizing ventricular function in man. Am Heart $J$ 1987;114: 1183-1191.

16. Mancini GBJ, Simon SB, McGillem MJ, LeFree MT, Friedman HZ, Vogel RA. Automated quantitative coronary arteriography: in-vivo morphologic and physiologic validation of a rapid method utilizing digital angiography. Circulation 1987;75:452-460.

17. Mathews DE, Farewell $T$. Using and Understanding Medical Statistics. Basel, Switzerland: Karger, 1988:79-87.

18. Neter J, Wasserman W. Applied Linear Statistical Models. Homewood, IL Richard D. Irwin, 1974:730.

19. Mathews DE, Farewell T. Using and Understanding Medical Statistics. Basel, Switzerland: Karger, 1988:156-166.

20. Multicenter Post-infarction Research Group. Risk stratification and survival after myocardial infarction. $N$ Engl $J$ Med 1983;309:321-336.

21. Little WC, Constaninescu M, Applegate RJ, Kutcher MA, Burrows MT, Kahl FR, Santamore WP. Can coronary angiography predict the site of a subsequent myocardial infarction in patients with mild-to-moderate coronary artery disease? Circulation 1988;78:1157-1166.

22. Ellis S, Alderman EL, Cain K, Wright A, Bowrassa M, Fisher L, and the participants of CASS. Morphology of left anterior descending coronary territory lesions as a predictor of anterior myocardial infarction: a CASS Registry Study. $J$ Am Coll Cardiol 1989:13:1481-1491.

23. White HB. Relation of thrombolysis during acute myocardial infarction to left ventricular function and mortality. $\mathrm{Am} J$ Cardiol 1990;66:92-95.

24. Klocke FJ. Cognition in the era of technology: "Seeking the shades of gray." $I$ Am Coll Cardiol 1990;16:763 769 .

25. Arnett EN, Isner JM, Redwood DR, Kent KM, Baker WP, Ackerstein H, Roberts WC. Coronary artery narrowing in coronary heart disease: comparison of cineangiographic and necropsy findings. Ann Intern Med 1979:91:350-359.

26. Kirkeeide RL, Gould KL, Parsel L. Assessment of coronary stenoses by myocardial perfusion imaging during pharmacologic coronary vasodilation. VII. Validation of coronary flow reserve as a single integrated functional measure of stenosis severity reflecting all its geometric dimensions. J Am Coll Cardiol 1986;7:103-113.

27. Glagov S, Weisenberg E, Zarins CK, Stankunavicius R, Kolettis GJ. Compensatory enlargement of human atherosclerotic coronary arteries. $N$ Engl J Med 1987;316:1371-1375.

28. Legrand V, Mancini GBJ, Bates ER, Hodgson JM, Gross MD, Vogel RA Comparative study of coronary flow reserve, coronary anatomy and results of radionuclide exercise tests in patients with coronary artery disease. $J \mathrm{Am}$ Coll Cardiol 1986;8:1022-1032.

29. White CW, Wright CB, Doty DB, Hiratzka LF, Eastham CL, Harrison DG, Marcus ML. Does visual interpretation of the coronary arteriogram predict the physiologic importance of a coronary stenosis? N Engl J Med 1984:310:819-824. 30. Stadius ML, Alderman EL. Coronary artery revascularization: critical need for, and consequences of, objective angiographic assessment of lesion scverity. Circulation 1990;82:2231-2234. 